\title{
Further reflections on actuarial recognition of nuclear holocaust hazard
}

\author{
Cecil J. NESBITT \\ University of Michigan, Ann Arbor, MI 48109-1003, USA
}

In a paper presented to the Twenty-Second Actuarial Research Conference, held in 1987 at the University of Toronto, a notation and mathematical model were developed to explore the impact of nuclear holocaust hazard on actuarial mathematics. The purpose of the present paper is to consider this hazard in relation to long-term income maintenance systems such as Social Security and retirement plans.

The paper begins with a brief recollection of the notations used in the Toronto paper. It then highlights the actuarial projections of the 1988 Annual Report of the Board of Trustees of U.S. Old-Age and Survivors Insurance and Disability Insurance Trust Funds. This is a very large system with current annual outgo of $\$ 220$ billion, and rapidly growing assets. Under the less optimistic of two intermediate projections, the combined trust funds are estimated to reach a level of $\$ 12$ trillion by the end of 2030 . Thereafter, the funds are projected to decline rapidly to exhaustion by 2050 . A simple difference equation, in the notation of the Toronto paper, is examined as a possible means of controlling the upward and downward changes in the trust funds if Congress periodically adjusts OASDI financing to satisfy the equation.

Next sections of the paper consider what recognition of nuclear holocaust hazard would mean for pension mathematics. The easiest situation to discuss is in regard to reserves for retired members and beneficiaries. A second matter is the calculation of optional retirement annuities, and could entail much numerical work. The funding for active members will bring up many questions, in particular, in regard to the actuarial assumptions.

In concluding sections, the paper attempts to measure the scientific worth of recognizing nuclear holocaust hazard in our actuarial mathematics, and the consequences thereof. One keeps coming back to the idea that the only practical way to recognize such hazard is by a specific component of the interest rate. Thereby, long-term financial transactions can proceed quite logically even in the presence of the hazard. But one essential step for world progress is to minimize nuclear holocaust hazard. To aid this process, actuarial science should seek its truths, and communicate them widely.

Keywords: Nuclear holocaust hazard, Social security, Pension mathematics.

\section{Introduction}

In a paper, presented to the 22nd Actuarial Research Conference [Nesbitt (1989)], I set up notations and a mathematical model for considering the recognition of nuclear holocaust hazard in the actuarial mathematics for an individual 'life aged $x$ years', the phrase in quotation marks being denoted by $(x)$. Here, we recall briefly those notations for subsequent use in regard to actuarial projections for Social Security, on an aggregate rather than individual basis, and for some aspects of pension mathematics.

We consider various consecutive years, $(k, k+$ $1)$, each specified by its beginning and ending times. By $v_{1}(k, k+1)$, we denote the present value at time $k$ of 1 due at time $k+1$, if ordinary discount (interest-in-advance) for the year is at annual rate $d_{1}(k)$. Then,

$v_{1}(k, k+1)=1-d_{1}(k)$,

and the corresponding effective annual rate of interest-in-arrears is

$i_{1}(k+1)=d_{1}(k) / v_{1}(k, k+1)$.

A further notation is

$v_{1}(h, k)=\prod_{g=h}^{k-1} v_{1}(g, g+1)$

for the present value at time $h$ of 1 due at time $k$ if discount rates are $d_{1}(g), g=h, h+1, \ldots, k-1$.

The annual discount rate for nuclear holocaust hazard was denoted by $d_{2}(k)$, and

$v_{2}(k, k+1)=1-d_{2}(k)$.

Then,

$v_{2}(h, k)=\prod_{g=h}^{k-1} v_{2}(g, g+1)$

discounts to time $h$ a unit due at time $k$ for nuclear holocaust in the interval $(h, k)$, such holocaust not having occurred before time $h$.

Also defined were composite factors

$$
\begin{aligned}
& v_{1,2}(k, k+1)=v_{1}(k, k+1) v_{2}(k, k+1) \\
& \begin{aligned}
d_{1,2}(k) & =1-v_{1,2}(k, k+1) \\
& =d_{1}(k)+d_{2}(k)-d_{1}(k) d_{2}(k) .
\end{aligned}
\end{aligned}
$$


For calculations pertaining to $(x)$, we introduced the annual rate of mortality $d_{3}(k)=q_{x+k}$, and

$v_{3}(k, k+1)=1-d_{3}(k)=p_{x+k}$.

One can form composite factors, such as

$v_{1,3}(k, k+1)=v_{1}(k, k+1) v_{3}(k, k+1)$,

similarly $v_{1,3}(h, k), v_{2,3}(h, k)$ and $v_{1,2,3}(h, k)$. Many relations follow therefrom. In particular, the net single premium for a whole life insurance of 1 payable at the end of the year of death of $(x)$ if nuclear holocaust has not intervened is

$$
\begin{aligned}
& A_{1,2,3}(0, \omega-x) \\
& \quad=\sum_{k=0}^{\omega-x-1} v_{1,2}(0, k+1) v_{3}(0, k) d_{3}(k) .
\end{aligned}
$$

Also, the actuarial present value of a unit life annuity-due to $(x)$, with recognition of nuclear holocaust hazard, is

$\ddot{a}_{1,2,3}(0, \omega-x)=\sum_{k=0}^{\omega-x-1} v_{1,2,3}(0, k)$.

Analogous to the relation, $1=d \ddot{a}_{x}+A_{x}$, one can show that

$$
\sum_{k=0}^{\omega-x-1} d_{1,2}(k) v_{1,2,3}(0, k)+A_{1,2,3}(0, \omega-x)=1
$$

by algebra or general reasoning [see formulas (5.1) and (6.3) of Nesbitt (1989)]. Also,

$$
\begin{aligned}
& \sum_{k=0}^{\omega-x-1} d_{1}(k) v_{1,2,3}(0, k)+A_{1,2,3}(0, \omega-x) \\
& =\sum_{k=0}^{\omega-x-1} d_{1,2}(k) v_{1,2,3}(0, k)+A_{1,2,3}(0, \omega-x) \\
& \quad+\sum_{k=0}^{\omega-x-1}\left[d_{1}(k)-d_{1,2}(k)\right] v_{1,2,3}(0, k) \\
& =1-\sum_{k=0}^{\omega-x-1} d_{2}(k) v_{1}(k, k+1) v_{1}(0, k) \\
& \quad \times v_{2,3}(0, k) \\
& \quad[\text { by use of }(1.11),(1.7) \text { and }(1.1)] \\
& =1-\sum_{k=0}^{\omega-x-1} v_{1}(0, k+1) v_{2,3}(0, k) d_{2}(k) .
\end{aligned}
$$

Here, the last summand represents the actuarial present value of the death claim payment lost in year $(k+1)$ by reason of nuclear holocaust in the year.

You will have observed that discount notations, $d$ and $v$, have been used for ordinary interest, nuclear holocaust, and mortality. Each of the corresponding rates operates in a distinctive way, different from that of the others. Nevertheless, there is a great deal of symmetry in the mathematical formulas such as (1.6), (1.7) and (1.10), but less in formulas such as (1.9) and (1.12). The theory can be enriched by probability interpretations but for this paper discount interpretations are appropriate.

\section{OASDI actuarial projections}

We start by highlighting the projected financing of Old-Age, Survivors and Disability Insurance (OASDI) in the United States. Short-range and long-range actuarial projections are contained in the reports of the Board of Trustees, and we shall refer to those in the 1988 report [Bot (1988)]. For these projections, four alternative sets of demographic, economic and programmatic assumptions are utilized with Alternative I labeled as 'optimistic' and Alternative III as 'pessimistic'. Alternatives II-A and II-B are labeled 'intermediate'. They share the same demographic assumptions but II-A assumes more robust economic growth than II-B. This carries implications over to the programmatic assumptions and bases [see Andrews and Beekman (1987)].

Various measures of actuarial status are used [Bot (1988), Bartlett (1981)]. Contingency fund ratio is the amount in the trust fund at the beginning of the year, including advance transfers for January, divided by that year's expenditures. This measure is used extensively for the short-range projections.

Figure 1 (Chart A from the Report) shows the OASDI contingency fund ratio for 1988, 41 percent, and the projected OASDI ratios for 1989-93, on the basis of all four sets of assumptions. Alternative II-B shows a 1992 ratio slightly in excess of 100 percent.

In regard to the long-range projections, we have the statements:

'In analyzing the actuarial status of OASDI for the next 75 years, several different mea- 


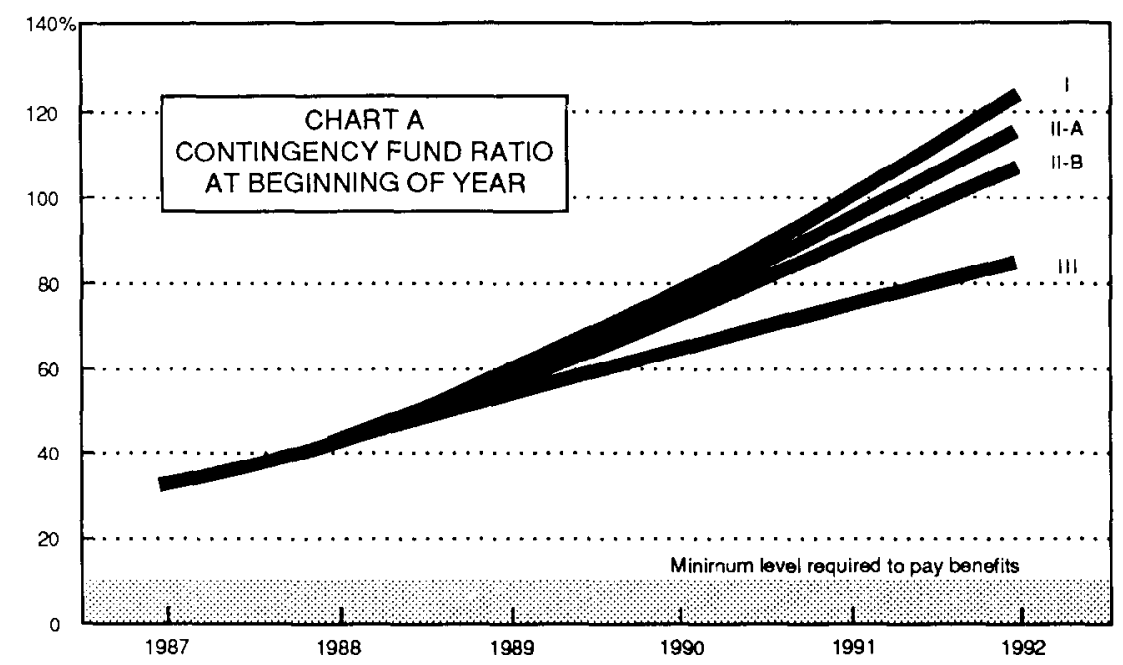

Fig. 1. Contingency fund ratio at beginning of year.

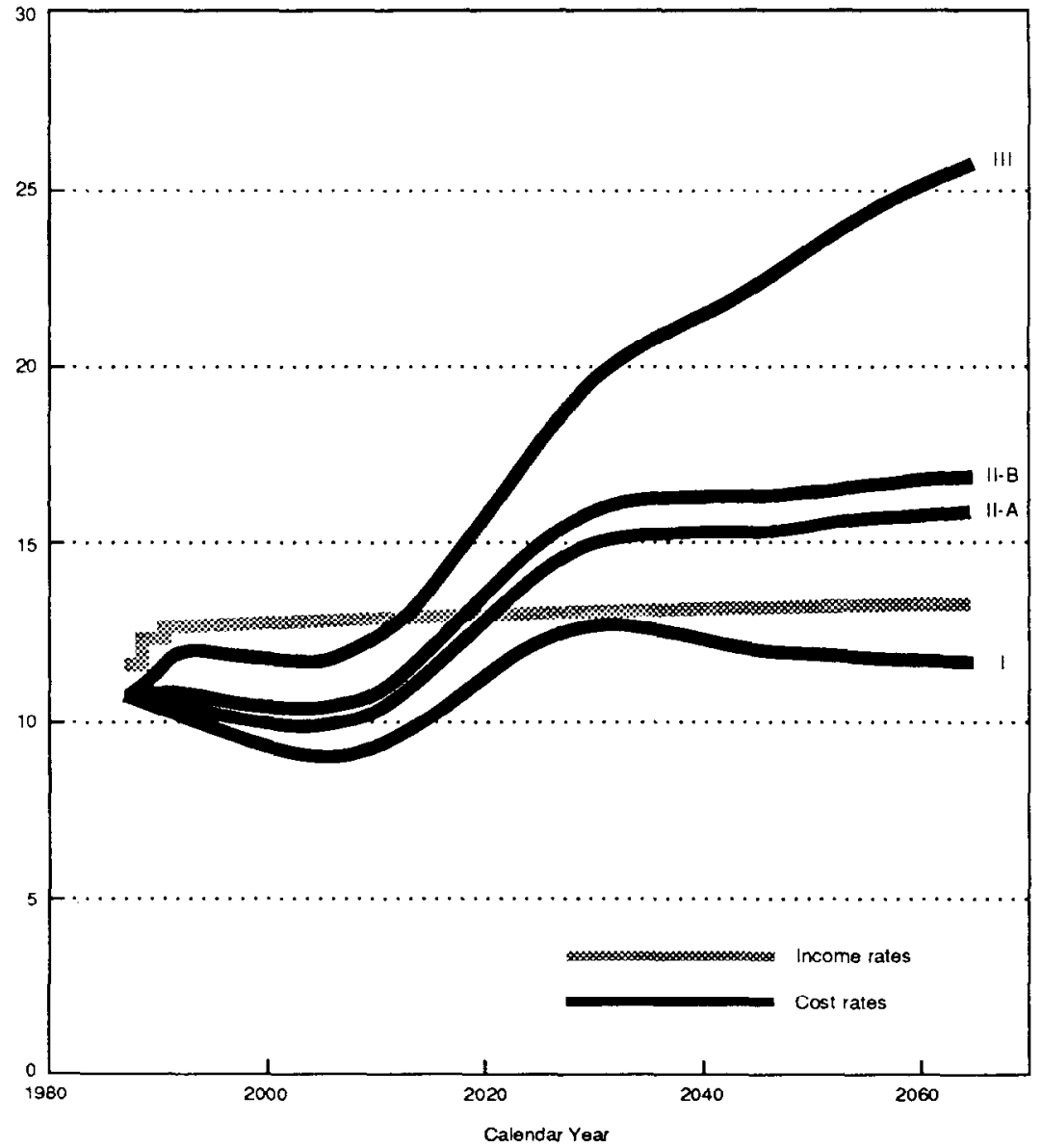

Fig. 2. Estimated OASDI income rates and cost rates by alternative, calendar years 1987-2065 (as a percentage of taxable payroll). 


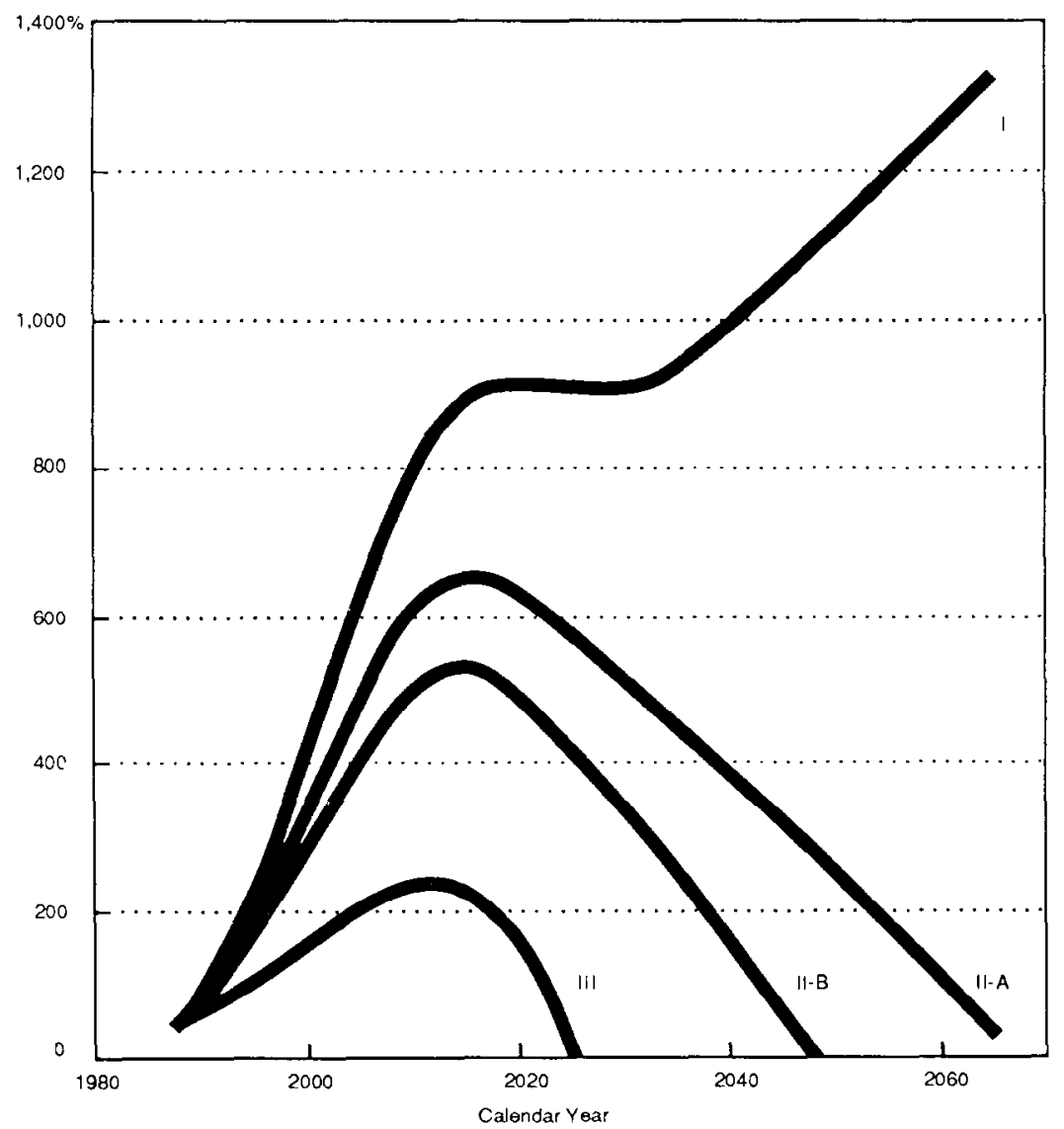

Fig. 3. Estimated contingency fund ratios, for OASI and DI trust funds combined, calendar years 1987-2065.

sures are commonly used. The income rate is the combincd OASDI employce-cmployer contribution rate scheduled in the law, plus the income from taxation of benefits, expressed as a percentage of taxable payroll. The cost rate is the annual outgo expressed as a percentage of taxable payroll.'

It is important to note that trust fund investment income is not included in the income rate.

Figure 2 [Figure 2 of Bot (1988)] exhibits the cost rates for each of the four Alternatives; and the income rates which do not vary much by alternative [cf. Bot (1988, Table 26)]. An excess of income for the next 25 years is indicated for all four Alternatives. If, however, contingency fund ratios are considered, we observe from Figure 3 [Figure 4 of Bot (1988)] that the ratio peaks about 2010 at slightly less than 250 percent for Alternative III, at 530 percent in 2015 for Alternative II-B, and soars to somewhat more than 1300 percent under optimistic Alternative I.
Another quotation from Bot (1988), with a parenthetical comment is:

'For this report, long-range actuarial balances are calculated using "level-financing" methodology. (Thereby, equivalent level percentages of future increasing taxable payroll replace the year-by-year income and cost rates, and the actuarial balance is the difference between the level percentages.) The methodology discounts future surpluses and deficits using the real rate of interest. It is the most appropriate for summarizing the financial status of the OASDI system over the 75-year period, a period in which the trust funds build up in the early years when income exceeds outgo and are subsequently depleted during the final years when expenditures are expected to exceed income.'

Table 1, a portion of Table 27 of Bot (1988), presents actuarial balances as defined above. 
Table 1

O^SDI actuarial balances by alternative, 1988-2062 (as a percentage of taxable payroll).

\begin{tabular}{|c|c|c|c|}
\hline & $\begin{array}{l}\text { Equivalent } \\
\text { level } \\
\text { income rate }\end{array}$ & $\begin{array}{l}\text { Equivalent } \\
\text { level } \\
\text { cost rate }\end{array}$ & $\begin{array}{l}\text { Actuaria } \\
\text { balance }\end{array}$ \\
\hline \multicolumn{4}{|l|}{ Alternative 1} \\
\hline 25 years: $1988-2012$ & 12.74 & 9.51 & 3.24 \\
\hline 50 years: $1988-2037$ & 12.80 & 10.57 & 2.23 \\
\hline 75 years: $1988-2062$ & 12.83 & 10.97 & 1.86 \\
\hline \multicolumn{4}{|l|}{ Alternative II-A } \\
\hline 25 years: $1988-2012$ & 12.77 & 10.14 & 2.63 \\
\hline 50 years: $1988-2037$ & 12.85 & 11.77 & 1.08 \\
\hline 75 years: $1988-2062$ & 12.91 & 12.83 & 0.08 \\
\hline \multicolumn{4}{|l|}{ Alternative II-B } \\
\hline 25 years: $1988-2012$ & 12.78 & 10.54 & 2.24 \\
\hline 50 years: $1988-2037$ & 12.87 & 12.34 & 0.53 \\
\hline 75 years: $1988-2062$ & 12.94 & 13.52 & -0.58 \\
\hline \multicolumn{4}{|l|}{ Alternative III } \\
\hline 25 years: $1988-2012$ & 12.82 & 11.72 & 1.11 \\
\hline 50 years: $1988-2037$ & 12.95 & 14.23 & -1.28 \\
\hline 75 years: $1988-2062$ & 13.07 & 16.49 & -3.42 \\
\hline
\end{tabular}

a Income rates take account of the beginning trust fund.

We conclude these highlights of Bot (1988), with a reference to its Appendix G - Long-Range Estimates of Social Security Trust Fund Operations in Dollars. The Appendix notes that longrange trust fund operations are not usually shown in dollar amounts because inflation makes such amounts non-comparable over time. Measures such as cost rates and income rates, expressed as percentage of taxable payroll, are more stable. Demand exists, however, for long-range dollar values, and these are presented together with sets of indices that may be used to deflate the magnitude of future dollar items.

A sample of such dollar amounts is given in Table 2.

Figures such as these were undoubtedly the source of the April 11, 1988 New York Times perceptive editorial 'Trillions, Trillions All Around'.

\section{Levers for controlling the level of the OASDI trust funds}

It is clear from the foregoing discussion of Bot (1988), that the OASDI trust funds will, under present law, increase rapidly over the next two decades, but later will reach a maximum and decrease rapidly. One is reminded of various papers concerned with funding equilibria that appear in long-term stable benefits programs [Bowers (1979), Treuil (1981)]. For the immediate future of the OASDI trust funds, these appear to offer little guidance. Eventually, some mathematical discussion of benefit outgo and tax income may be enlightening. Another source is Trowbridge's (1977) paper in regard to the assessment systems that have emerged in France. One gathers that benefits are expressed in terms of units whose value is adjusted as financial resources require, thus achieving actuarial equilibrium. Again, there may be ideas to be gained from this approach but their implementation would seem to require a massive restructuring of OASDI, with all the consequent debate and persuasion that would be entailed. It appears simpler to work within the present structure, particularly in terms of the short-range projections. In the following proposal for providing actuarial-financial control of

Table 2

Estimated operations of OASDI trust funds (alternative II-B, in billions). ${ }^{a}$

\begin{tabular}{llrrrr}
\hline $\begin{array}{l}\text { Calendar } \\
\text { year }\end{array}$ & $\begin{array}{l}\text { Income } \\
\text { excluding } \\
\text { interest }\end{array}$ & Interest & $\begin{array}{l}\text { Total } \\
\text { income }\end{array}$ & $\begin{array}{l}\text { Total } \\
\text { outgo }\end{array}$ & $\begin{array}{l}\text { Assets at } \\
\text { end of year }\end{array}$ \\
\hline 1990 & $\$ 293.3$ & $\$ 16.3$ & $\$ 309.5$ & $\$ 252.2$ & $\$ 211.9$ \\
2000 & 547.9 & 83.6 & 631.5 & 446.8 & $1,409.4$ \\
2015 & $1,302.6$ & 383.7 & $1,686.3$ & $1,203.7$ & $6,763.0$ \\
2030 & $2,898.7$ & 692.0 & $3,590.7$ & $3,524.5$ & $11,837.5$ \\
2045 & $6,422.5$ & 251.8 & $6,674.3$ & $7,966.8$ & $3,799.4$ \\
\hline
\end{tabular}

a After 2047, action required to avoid exhaustion. 
OASDI, we shall also recognize nuclear holocaust hazard.

For this purpose, the following notations will be used:

$F(k)=$ the value in dollars of the OASDI trust funds at time $k$, ignoring, for simplicity, details such as advance transfers from the Treasury.

$I(k)=$ the value at time $k$ of projected income for year $(k, k+1)$, exclusive of interest.

$O(k)=$ the value at time $k$ of projected outgo for the year $(k, k+1)$.

Then, if $i_{1,2}(k+1)$ is the effective annual rate of interest, equivalent to $d_{1,2}(k)$, the composite rate of discount based on $d_{1}(k)$ and $d_{2}(k)$ defined in Section 1, we have

$$
\begin{aligned}
& {[F(k)+I(k)-O(k)]\left[1+i_{1.2}(k+1)\right]} \\
& \quad=F(k+1) .
\end{aligned}
$$

Because we ignore advance transfer payments, we shall consider the fund ratio $[F(k) / O(k)]$ rather than the Report's contingency fund ratio. Suppose now that at time $k$, the fund ratio is $c$, that is, $F(k)=c . O(k)$, and that we wish to maintain the ratio at that level. From (3.1), we require

$$
\begin{aligned}
& {[(c-1) O(k)+I(k)]} \\
& \quad=v_{1,2}(k, k+1)[c \cdot O(k+1)]
\end{aligned}
$$

or

$$
\begin{aligned}
I(k)= & v_{1,2}(k, k+1)[c \cdot O(k+1)] \\
& -(c-1) \cdot O(k) .
\end{aligned}
$$

In particular, for the frequently recommended case, $c=1$,

$I(k)=v_{1,2}(k, k+1) O(k+1)$.

If nuclear holocaust hazard were negligible, (3.3) would become

$I(k)=v_{1}(k, k+1) O(k+1)$.

If nuclear holocaust hazard is not neglible, then

$$
\begin{aligned}
v_{1,2}(k, k+1) & =v_{1}(k, k+1) \cdot v_{2}(k, k+1) \\
& <v_{1}(k, k+1) .
\end{aligned}
$$

It appears that the presence of nuclear holocaust hazard reduces the cost of maintaining the fund ratio at a level of 1 . By substituting $v_{1}(k, k+1)[1$ $\left.-d_{2}(k)\right]$ for $v_{1,2}(k, k+1)$, we can rewrite (3.3) as

$$
\begin{aligned}
I(k)= & v_{1}(k, k+1) O(k+1) \\
& -d_{2}(k) v_{1}(k, k+1) O(k+1) .
\end{aligned}
$$

The term $d_{2}(k) v_{1}(k, k+1) O(k+1)$ states explicitly the afore-mentioned cost reduction when nuclear holocaust hazard is recognized.

The situation is, however, very complex and can be evaluated accurately only as experience unfolds. The presence of nuclear holocaust hazard over a period of years may influence fertility rates, and entail the consequences thereof. As discussed in Nesbitt (1989), nuclear holocaust hazard can have a drastic impact on survival rates. Also, interest rates may be higher by a nuclear holocaust component. A warning should be sounded here: one must avoid duplicate recognition. If nuclear holocaust hazard is recognized in the assumed interest rates, then survival rates should be taken from the usual sources. Other assumptions that nuclear holocaust may modify are wage increase rates, consumer price increases, unemployment rates, and indeed general morale ranging from bleak pessimism to constructive hope based on intelligent and informed actions to deal with the hazard. By constant observation and analysis, trends can be recognized and incorporated into the actuarial projections, and the results evaluated.

Returning to (3.3), let us consider how it may be used to maintain the fund ratio at a level of 1 , that is, at 100 percent. Currently, that ratio is increasing toward 100 percent. When it reaches that level in the early 1990's, it is within Congress' power to maintain it there by increasing outgo, $O(k+1)$, or decreasing income, $I(k)$, or by some combination thereof. In view of the long-range projections, and the projected ultimate exhaustion of the fund if tax rates remain unaltered, such increase of outgo would be unwise.

Decreasing income by temporary decrease in the OASDI tax rates would be reasonable, and should be done periodically in the light of the short-range projections and (3.3). This would still permit a large dollar fund to accumulate, as can be seen from the outgo column of Table 2 , and recalling that (3.3) requires the fund at time $k$ to the equivalent to $O(k+1)$, the value at time $k+1$ of the outgo for year $(k+1, k+2)$. Such a fund should suffice to quell the anxiety of future beneficiaries as to whether money will be available when their benefits come on stream.

Fairly early in the next century if OASDI tax rates have been reduced, there will be a funding turn around, tending to decrease the fund ratio below 100 percent. At that time, and at subse- 
quent times thereafter, it may be necessary for Congress to restore tax rates to previously legislated levels, and in the longer term, to increase them further if the fund ratio is to be maintained at 100 percent. This will increase $I(k)$. An alternative lever, which like the tax increase, would engender opposition, consists of Congress decreasing the benefit outgo, the main element of $O(k+1)$, by modification or postponement of cost-of-living increases based on the Consumer Price Index. A precedent for postponement has been established already by the 1983 Amendments.

Still a third lever to be used when the fund ratio is under pressure is for Congress to increase the income-taxation of Social Security benefits, and thereby increase $I(k)$. Again, a precedent for this action has been established by the 1983 Amendments.

With these powerful levers available to it, the Congress can, if it wills, maintain the fund ratio at the reasonable level of 100 percent. These levers are known, and all have been used before. But both the public and the Congress should become familiar with them, and expect their use when from time to time circumstances may require their application.

\section{Retired member pension reserves}

It is relatively easy to discuss the effect of recognizing nuclear holocaust hazard in reserves for retired members and their beneficiaries under a given pension plan. For this purpose, we begin with the recursion formula (6.4) of Nesbitt (1989), namely,

$$
\begin{aligned}
\ddot{a}_{1,2,3}(k, \omega-x)= & 1+v_{1,2,3}(k, k+1) \\
& \times \ddot{a}_{1,2,3}(k+1, \omega-x) .
\end{aligned}
$$

On substituting $v_{1,3}(k, k+1)\left[1-d_{2}(k)\right]$ for $v_{1.2 .3}(k, k+1)$, we obtain

$\ddot{a}_{1,2,3}(k, \omega-x)-v_{1,3}(k, k+1)$

$$
\begin{aligned}
& \times \ddot{a}_{1,2,3}(k+1, \omega-x) \\
= & 1-v_{1,3}(k, k+1) d_{2}(k) \ddot{a}_{1,2,3}(k+1, \omega-x) .
\end{aligned}
$$

Multiplication by $v_{1,3}(0, k)$ and summation over $k$ gives

$$
\begin{aligned}
& \ddot{a}_{1,2,3}(0, \omega-x) \\
& =\ddot{a}_{1,3}(0, \omega-x)-\sum_{k=0}^{\omega-x-1} d_{2}(k) v_{1,3}(0, k+1) \\
& \quad \times \ddot{a}_{1,2,3}(k+1, \omega-x) .
\end{aligned}
$$

Here, $\ddot{a}_{1.3}(0, \omega-x)=\ddot{a}_{x}$ based on ordinary interest and mortality. Thus, the actuarial present value for a life annuity with recognition of nuclear holocaust hazard is less than the usual actuarial present value by the additional reserves deleted by nuclear holocaust hazard.

A slightly different view is given by arranging (4.2) as

$$
\begin{aligned}
& \ddot{a}_{1,2.3}(0, \omega-x)+\sum_{k=0}^{\omega-x-1} d_{2}(k) v_{1,3}(0, k+1) \\
& \quad \times \ddot{a}_{1,2,3}(k+1, \omega-x) \\
& =\ddot{a}_{1,3}(0, \omega-x)
\end{aligned}
$$

Here, (4.3) asserts that the reserve $\ddot{a}_{1,2,3}(0, \omega-x)$, recognizing nuclear holocaust hazard, plus the present value of the discounts at rate $d_{2}(k)$ on the reserve expected to be required at time $k+1$, $k=0,1, \ldots, \omega-x-1$, suffice to provide the ordinary life annuity reserve, $\ddot{u}_{1,3}(0, \omega-x)$. The redundancy in exposition here is deliberate. In (4.2), one views nuclear holocaust as a cataclysmic contingency, while in (4.3) one asserts that in practice it may be taken into account as a special factor in the interest assumption. In either case, one sees that $\ddot{a}_{1,2,3}(0, \omega-x)$ is less than $\ddot{a}_{1,3}(0, \omega$ $-x)$ by an amount depending on $d_{2}(k), k=$ $0,1, \ldots, \omega-x-2$ (since the summand at $\omega-x-$ 1 is zero). Thus, pension fund reserves for retirees and beneficiaries will be smaller if nuclear holocaust hazard is duly recognized.

One might also recognize nuclear holocaust hazard by using $v_{2,3}(k, k+1)$, the composite survival rate for year $(k, k+1)$, but this does not provide a means for offsetting annuity losses when nuclear holocaust does not occur. Recognition of nuclear holocaust by an interest component is more feasible. To clarify this, one can rewrite (4.1) as

$$
\begin{aligned}
\ddot{a}_{1,2,3}( & k, \omega-x)+d_{2}(k) v_{1,3}(k, k+1) \\
& \left.\times \ddot{a}_{1,2,3}(k+1) \omega-x\right) \\
=1 & +v_{1,3}(k, k+1) \ddot{a}_{1,2,3}(k+1, \omega-x) .
\end{aligned}
$$

Formula (4.4) asserts that the annuity reserve at time $k$ (with recognition of nuclear holocaust hazard) plus supplementary interest-in-advance $d_{2}(k)$ on

$\alpha=v_{1,3}(k, k+1) \ddot{a}_{1,2,3}(k+1, \omega-x)$ 
provides the payment of 1 due at time $k$ plus the amount $\alpha$ needed to provide the annuity reserve at time $k+1$.

Formulas analogous to (4.2), (4.3) and (4.4) can be obtained by having $d_{1}(k)$ play the role of $d_{2}(k)$, and similarly for $d_{3}(k)$. These analogous formulas have insight for theory but may not be of interest in practice.

A final comment is that if retirement incomes are indexed, some additional consideration may be necessary. Such indexing is often restricted, so that the income increases can be predetermined, at least approximately.

\section{Optional annuities at retirement}

In many cases, pensions are not paid on a straight life annuity basis. Instead, a variety of optional annuities are available which may involve a period certain, or the survival of a second life. For simplicity of notation, we consider the optional annuity form providing for an annuity-certain for $n$ years and for life thereafter so long as $(x)$ survives. The conversion factor, for annual payment annuities-due, with recognition of nuclear holocaust hazard, is

$$
\frac{\ddot{a}_{1,2,3}(0, \omega-x)}{\ddot{a}_{1,2}(0, n)+v_{1,2,3}(0, n) \ddot{a}_{1,2,3}(n, \omega-x)} \text {. }
$$

How this factor, and similar factors for other optional annuity forms, vary with degree of nuclear holocaust hazard assumed, could require extensive numerical calculation. The results would be related to those based on increasing the interest rate assumption but the latter might be on a more constant rather than year-by-year varying basis.

\section{Pension funding for active members}

A full scale investigation of how nuclear holocaust hazard might be recognized in pension funding for active members could be very extensive, and has not been undertaken here. Brief consideration of how the actuarial assumptions might be influenced by such recognition will be the extent of this section.

There have been repeated statements that the practical way of recognizing nuclear holocaust hazard in long-term financial transactions is by composition with the rate of interest (investment return). This increases the interest rates assumed, and thereby increases accumulations under defined contribution plans and lowers costs under defined benefit plans.

The retirement rates assumed have significant impact on the funding costs of defined benefit pension plans. Over a long-term, members' apprehension of nuclear holocaust might lead to more early retirements.

Another significant assumption for pension funding costs is salary increase rates which often have price increases as a major component. The long-term impact of recognizing nuclear holocaust hazard might well involve increasing trends for salaries and prices.

For active members, the effect of recognizing nuclear holocaust hazard is uncertain. The ready answer is that, viewed as a discount cause, nuclear holocaust hazard should reduce pension funding costs for active members of a defined benefit plan. But over a long term, there may be unfavorable changes in other valuation factors, such as retirement rates, or salary increase rates, and these may offset the discount effect of the hazard.

\section{Is this true actuarial science?}

In his address to the Annual Actuarial Research Conference, at the University of Manitoba, the recently deceased Edmund C. Berkeley gave as his Proposition 10:

'It is not right for actuaries and managers in insurance companies to exclude the risks of nuclear weapons, nuclear fission energy, war, and genocide in (a) policy contracts, (b) thinking and discussion, and (c) political and professional action.' [Berkeley (1982).]

The part of this proposition that relates to nuclear holocaust has been growing in my mind since then.

In Nesbitt (1989) and this paper we have worked with the discount factors

$$
\begin{aligned}
& v_{1,2,3}(k, k+1) \\
& =v_{1}(k, k+1) v_{2}(k, k+1) v_{3}(k, k+1) \\
& =\left[1-d_{1}(k)\right]\left[1-d_{2}(k)\right]\left[1-d_{3}(k)\right] \\
& =1 /\left\{\left[1+i_{1}(k+1)\right]\left[1+i_{2}(k+1)\right]\right. \\
& \left.\times\left[1+i_{3}(k+1)\right]\right\} .
\end{aligned}
$$


By making various combinations of the factors, and by summation, one gets all sorts of meaningful relations. For the present paper, because we have been thinking mainly about projected aggregate cash flows, discount notations and interpretations seem appropriate. But, as indicated in Nesbitt (1989), in regard to individual lives, there is also much probability theory to explore. The actuarial mathematics with recogniztion of nuclear holocaust hazard rings as true as any of our more standard models. It allows many illuminating interpretations. Thereby, we get closer to the truth of our time.

I am convinced, however, that the world cannot, and will not, tolerate a significant level of nuclear holocaust hazard for an indefinite period of time. Thus, actuarial science with recognition of nuclear holocaust hazard should not be the ultimate mathematical basis for our insurance and benefit systems. But actuarial science has immediate, supreme responsibility which it has been slow to assume, to demonstrate how nuclear holocaust hazard can impair all our financial security systems, and survival itself. Thereby, actuarial science could hasten the day when nuclear holocaust hazard will be a negligible factor, and can once again be ignored properly in actuarial calculations. The models developed on the way may then prove useful in other life-threatening circumstances.

In the next section, some of the immediate steps in the educational process of recognizing nuclear holocaust hazard are indicated.

\section{Demonstrating the actuarial impact of nuclear holocaust hazard}

Emerging from the Toronto paper [Nesbitt (1989)] are two main ideas. One concerns the impact of nuclear holocaust hazard on measures of survival such as expectation of future life and median survival age. These measures are understood imperfectly by the public, and in the current presence of nuclear holocaust hazard are in many presentations quite misleading. Actually, great real progress in public health, as calculated by improvements in such measures, could be accomplished through minimizing nuclear holocaust hazard.
The second main idea is that in the current world, all long-term financial payments should be discounted for nuclear holocaust hazard, and this is a practical way to incorporate the hazard into actuarial calculations. This second idea has been pursued in this paper in relation to actuarial projections for Social Security, and to some aspects of pension funding mathematics.

Much work could be done on alternative models incorporating nuclear holocaust hazard, such as fully continuous models, and various types of multiple decrement models [cf. Nesbitt and Van Eenam (1948), Bowers et al. (1986) Ch. 9]. That work, together with supporting illustrations, could strengthen actuarial statements concerning nuclear holocaust hazard. The level of nuclear holocaust hazard is largely unknown, but a range of alternative assumptions concerning such level allows one to proceed. There is much opportunity for actuarial researchers and teachers to contribute to theory recognizing nuclear holocaust hazard, and to lead in discussions of why, how and when to minimize such hazard.

My final observation is that life insurance has been barely touched on in Nesbitt (1989), and I have not discussed partial nuclear holocaust which may require more mathematical apparatus than the extreme case of total holocaust.

\section{References}

Nesbitt, Cecil J., (1989). Exploration of actuarial mathematics with recognition of nuclear holocaust hazard, Proceedings of Twenty-Second Annual Actuarial Research Conference. Actuarial Research Clearing House. Society of Actuaries, Chicago, IL. forthcoming.

Board of Trustees (Bot) (1988). 1988 Annual report of the Board of Trustees of the Federal Old-Age and Survivors Insurance and Disability Insurance Trust Funds. House document 100-192, May. Government Printing Office, Washington, DC.

Andrews, George H. and John A. Beekman (1987). Actuarial Projections for the Old-Age, Survivors, and Disability Insurance Program of Social Security in the United States of America. Actuarial Education and Research Fund, Schaumburg, 1L.

Bartlett, Dwight K. III (1981). Measures of actuarial status for social security: Retrospect and prospect. Transactions of the Society of Actuaries XXXIII, 541.

Bowers, Newton L. Jr., James C. Hickman and Cecil J. Nesbitt (1979). The dynamics of pension funding: Contribution theory. Transactions of the Society of Actuaries XXXI, 93. 
Treuil, Pierre W. (1981). Fund development of an earnings related social insurance plan under stabilized conditions. Transactions of the Society of Actuaries XXXIII, 231.

Trowbridge, J.R. (1977). Assessmentism - an alternative to pension funding. Journal of the Institute of Actuaries 104, 173.

Berkeley, Edmund C. (1982). Society, computers, thinking and actuaries, Proceedings of the 16th Annual Actuarial Re- search Conference. Actuarial Research Clearing House 1982.1, 11.

Nesbitt, Cecil J. and Marjorie L. Van Eenam (1948). Rate functions and their role in actuarial mathematics, The record, American Institute of Actuaries XXXVII, 202.

Bowers, Newton L. Jr., Hans U. Gerber, James C. Hickman, Donald A. Jones and Cecil J. Nesbitt (1986). Actuarial Mathematics. Society of Actuaries, Schaumburg, IL, Ch. 9. 